\title{
Market Incentives for Business Innovation: Results from Canada
}

\author{
Charles Bérubé • Marc Duhamel • Daniel Ershov
}

Received: 21 April 2011 /Revised: 7 December 2011

Accepted: 15 December 2011 / Published online: 19 January 2012

(C) Her Majesty the Queen in Right of Canada 2012

\begin{abstract}
Are more competitive industries more innovative? Empirical investigation into various theories of innovation in industrial organization, agency theory, or endogenous growth, make diverse predictions with respect to this long-standing open question in economics. In this paper, we investigate the empirical relationship between competition intensity and firm innovation using a new micro-database containing a large sample of Canadian manufacturing enterprises over the 2000-05 period. Using three different measures of competition intensity, we find evidence that competition intensity is positively related to firm-level expenditures on research and development (R\&D) in Canadian manufacturing industries. However, we also find that this relationship is dampened when more firms are further from the technological frontier of their industry. Nevertheless, the results provide evidence for a Schumpeterian interpretation, whereby market power can increase business incentives for innovation when many firms are technological laggards.
\end{abstract}

Keywords competition intensity $\cdot$ innovation $\cdot$ firm performance

JEL Classification $\mathrm{D} 4 \cdot \mathrm{L} 1 \cdot \mathrm{L} 6 \cdot \mathrm{O} 31 \cdot \mathrm{O} 51$

The views and opinions expressed herein are not purported to be those of Industry Canada or the Government of Canada. Any errors or omissions remain the sole responsibility of the Authors. We would like to thank participants from the Canadian Economic Association and the 8th Annual International Industrial Organization conferences for their comments. A special thanks to Michael Peneder, Catherine Beaudry, Ryan Kelly, François Rimbaud, Annette Ryan and an anonymous referee for their suggestions and insightful comments. We gratefully acknowledge the assistance from the Science Innovation and Electronic Information Division at Statistics Canada for assembling and making this experimental dataset available to us.

C. Bérubé $(\square)$

Economic Research and Policy Analysis Branch, Industry Canada, Ottawa, Canada

e-mail: charles.berube@ic.gc.ca

M. Duhamel

Canadian Institute for Research on Public Policy and Public Administration, Université de Moncton, Moncton, Canada

e-mail: marc.duhamel@umoncton.ca

D. Ershov

Telecommunications Policy Branch, Industry Canada, Ottawa, Canada e-mail: daniel.ershov@ic.gc.ca 


\section{Introduction}

Are more competitive industries more innovative? There is by now a very large literature on this complex question, going back at least to Schumpeter (1934) and continuing with Arrow (1962). ${ }^{1}$

Theories of innovation in industrial organization, agency theory, or endogenous growth make diverse predictions with respect to this long-standing open question in economics. In general, the theoretical literature often oscillates between arguing for the positive and negative effects of competitive pressure on business innovation. For example, according to the popular interpretation of Schumpeter's (1934) work, greater competition reduces postinnovation rents, thereby limiting the incentive to innovate. ${ }^{2}$ Other popular models of firm innovation also suggest that innovation decreases with the level of competitive pressure. ${ }^{3}$ Other models (e.g. Aghion et al. 1997; 2001) predict that competitive pressure exerts a positive influence on firms' incentives to innovate. Empirical research using structural measures of competition (such as Lerner Index) have done little to settle this debate.

In this paper, we investigate the empirical relationship between competition intensity and firm innovation using three different measures of competition intensity and include, among other explanatory variables, a measure of industry distance to technological frontier (à la Aghion et al. 2005) to control for the toughness (or neck-and-neckness) of competition. Using a business micro-data set containing a large pooled cross-section of Canadian manufacturing enterprises covering the period 2000-05, we find some evidence that competition intensity is positively related to firm-level expenditures on research and development (R\&D) in Canadian manufacturing industries. The results also show that the impact of competition intensity greatly diminishes once we take into account the firms' distance from the technological frontier of their industry. Indeed, the results imply that if the distribution of firms is greatly skewed towards a relatively high distance to the technology frontier of the leading firm, a factor that can influence negatively the intensity or the quality of competition, the impact of competition intensity could prove to be negative.

This paper contributes to the extensive empirical literature that examines the impact of competition intensity on innovation. Empirical efforts in this field ceased in the mid-eighties after studies failed to find residual effects of market structure using cross-sectional data when controlling for industry "fixed effects" (Scott 1984) or introducing proxies for the conditions underlying the fixed effects (Levin et al. 1985). ${ }^{4}$ The consensus was that market structure and innovative behavior were jointly determined by technological opportunity (the returns to investment in R\&D, Scherer 1965), appropriability (the likelihood of the firm being able to appropriate returns, Arrow 1962) and market size (the base over which to capture the returns, Schmookler 1966). Theories of innovation agree on the factors affecting the innovative behavior of firms, but not on the directionality.

Demsetz (1973) describes the limitations of the empirical measures of market power used in the Structure-Conduct-Performance on the basis of their incapacity to separate market power from technical efficiency and superior performance. Empirical tests of the market

\footnotetext{
${ }^{1}$ For a summary of these two models, see Tirole (1988).

${ }^{2}$ It remains vague whether Schumpeter (1934) perceived the higher monopoly returns to innovation to be influenced by the monopolists' larger size or greater market power.

${ }^{3}$ In particular, see Salop (1977), Dixit and Stiglitz (1977), Loury (1979), Dasgupta and Stiglitz (1980), Spence (1984), Romer (1990), Aghion and Howitt (1992), Grossman and Helpman (1991).

${ }^{4}$ The fading interest by economists on the empirical relationship between competition and innovation also coincides with the disenchantment with traditional measures of market power (i.e. CRx, HHI, Lerner, and price-cost margins) in industrial organization following Demsetz (1973).
} 
structure and innovation hypotheses have used concentration or mark-up measures rather than more structural measures considered in industrial organization. ${ }^{5}$ In general, these tests have been cross-sectional comparisons of industries using different measures of innovation and the results have been equivocal. Tests tend to indicate that innovation is higher in industries with greater concentration, but those effects disappear as controls for industry are introduced (capturing conditions that jointly affect innovation and market structure). The recent renaissance of the empirical approach to the question by Aghion et al. (2005), with the possibility of a non-monotonic inverted-U relationship between competition and innovation first hinted by Scherer (1967), does little to resolve the theoretical dispute.

Thus, we can only wonder whether the lack of agreement between theory and evidence comes from the absence of robust theoretical predictions resulting from specious theoretical parameterization of business innovation, or perhaps because the empirical evidence is based on poor measures of competition intensity that fail to recognize the importance of the heterogeneity of efficiency between firms for the equilibrium "quality" of competitive pressure.

Given the evidence of extensive productivity heterogeneity between firms within an industry, and its theoretical importance to the quality of competition intensity and market selection, empirical results based on any measure of competition intensity are difficult to interpret. ${ }^{6}$ Duhamel and Kelly (2009) point out that:

"Most empirical study relied on two common variations of the Lerner index to measure competition intensity at the industry level. ${ }^{7}$ Although they have been used successfully in the empirical literature, the factors that can affect the measured Lerner index of an industry are not limited to competition. In particular, the measure is known to provide the wrong inference when the industry is concentrated and firms are heterogeneous or when the market is poorly delineated. ${ }^{8,}$

Using data from the same source as in his paper, the next chart shows an important nonlinear negative relationship between competition intensity (measured by Boone's Profit elasticity measure) and the average distance to the technology frontier of firms in an industry (Fig. 1). ${ }^{9}$

The difficulties of measuring competition in the particular circumstances of each industry cannot be ignored given the importance of the empirical relationship between competition and innovation.

In particular, it is important for a measure not only to capture the extent of product substitutability that determines the perceived competitive pressure within an industry, but also other characteristics that determine the competitive equilibrium such as the heterogeneity of the cost and product line obsolescence between firms.

For example, in the classic asymmetric homogeneous product Bertrand-duopoly equilibrium, the most efficient firm charges a price above its marginal cost, the competitive price of the inefficient firm, and earns positive economic profits. What would be the incentive to innovate compared to another industry where both firm compete on equal marginal cost? ${ }^{10}$

\footnotetext{
${ }^{5}$ For example, see Schmalensee (1989) and also Reiss and Wolak (forthcoming).

${ }^{6}$ Amongst others, see Duhamel and Ershov (2008) for an elaboration of the importance of this observation in the context of Canadian industries.

${ }^{7}$ The other variation is the price-cost markup. In particular, see Hall (1988), Roeger (1995).

${ }^{8}$ For example, see Schmalensee (1989) and more recently Thille (2011).

${ }^{9}$ In particular, see Duhamel (2011).

${ }^{10}$ See Tirole (1988).
} 


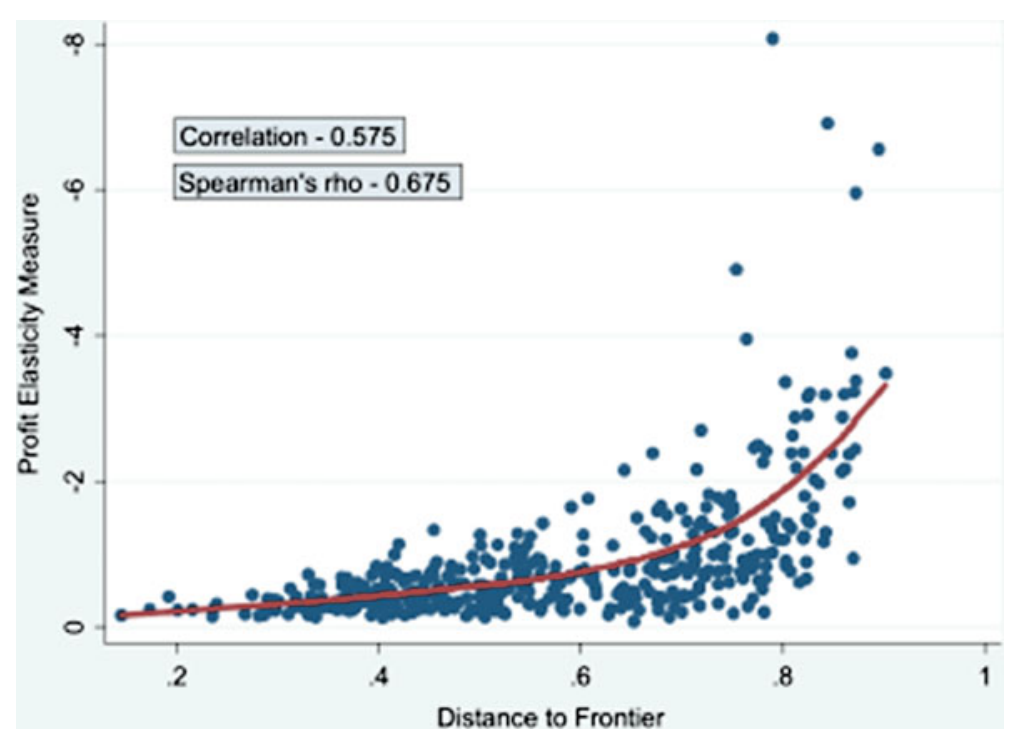

Fig. 1 Profit elasticity and average distance to technology frontier in Canadian industries

The larger the efficiency asymmetry between the two firms, the smaller will be the difference between the post-innovation and pre-innovation profits, ceteris paribus.

Vives (2008) revisits the effects of competitive pressure on process and product innovation using general symmetric oligopoly models of competition (strategic substitutes and complements), where investments in innovation by firms always yields some positive innovation outcomes (i.e. non-tournament/patent-racing models). Motivated by the lack of agreement between the theory and empirics of innovation and competition, he finds R\&D efforts increase or decrease depending on the factor driving increased competition intensity, provided that the total market size does not shrink. Again, these ambivalent theoretical predictions about factors that are commonly viewed as increasing competition run contrary to the empirical evidence that commonly rely on commonly used structural measure of competition and suggest that factors that influence the quality of competition (e.g. marginal cost asymmetry, product obsolescence, and other non-price competition attributes) are important factors in the relationship between competition and innovation. ${ }^{11}$

Boone $(2008 \mathrm{a}, \mathrm{b})$ proposes a new approach to measure competition that takes into account the heterogeneity of efficiency of firms in a market. His approach is based on the idea that competition rewards efficiency. More efficient firms will have higher market shares and higher profits than less efficient ones. In a more competitive market this effect should be stronger. ${ }^{12}$ He shows that the relative profit of a firm compared to a reference firm is a monotonically decreasing function of the relative marginal cost of the firm compared to the reference firm. This approach, aiming to capture the competitive interaction between competitors, is very similar to other recent approaches used in the economic growth literature (e.g. Aghion et al. 1997; 2005 and Acemoglu et al. 2006) which combine industry profit margins with a measure of distance to the technological frontier to capture the effects of heterogeneity of efficiency of firms on competitive pressure and market selection. Boone's methodology,

\footnotetext{
${ }_{11}$ In particular, see Geroski (1995), Nickell (1996), Blundell et al. (1999), Symeonidis (2002a, b).

12 See Budd et al. (1993).
} 
however, differs from most measures of competition intensity in that it does not presuppose the causes of changes in competition intensity (e.g. changes in market power for firms, entry or exit of competitors, changes in regulation); it simply observes that competition has changed and points out the direction of the change. In a sense, it is an agnostic structural measure of competition intensity.

We depart from previous empirical studies the relationship between competition and innovation in Canada in two important ways. First, this paper is the first one that takes into account the complex nature of the quality of competitive pressure with respect to incentives for innovation by taking into account the firm's relative efficiency with respect to its competitive peers (the distance-to-frontier effect). ${ }^{13}$ Second, we estimate the same reduced-form model using three different measures of competition using a pooled crosssection of quasi-longitudinal firm-level observations of innovation and competition intensity, effectively forming an unbalanced panel dataset. In doing so we show that the quality of competition is an important factor because it influences the marginal incentives of firms to engage in $R \& D$ activities, whether it originates from more technologically advanced manufacturing firms or from more innovative product offerings.

The rest of the paper proceeds as follows. First, we describe the empirical approach that decomposes the effects of competition and efficiency heterogeneity into its effects on firmlevel innovation efforts. Next, we describe the data. Section 4 then discusses the results. And finally, we outline the conclusions and discuss the implications of this study.

\section{The empirical model}

To address the issues raised above, we opt for a basic and general empirical model relating competition intensity, distance to the technological frontier, and business innovation that takes the following form (using the notation $f$ to index firms, $i$ for industries, and $t$ for time):

$$
I_{f i t}=g\left(\mu_{f i t}, D_{i t}, X_{f i t}\right)
$$

where $I$ is a measure of a firm's effort towards innovation, $\mu$ is a measure of competition intensity at the firm- or industry-level, $D$ is the average distance to the technology frontier at the industry-level, and $X$ is a vector of other covariates influencing this general relationship.

The model shares the same features as the empirical analysis in Aghion et al. (2005), where competition intensity interacts with the industry's average distance to the technological frontier to determine the pre-innovation incentives to innovation relative to the postinnovation market incentive. ${ }^{14}$ Our empirical approach also includes an attempt to test whether different competition intensity variables, including the profit elasticity (PE) measure proposed by Boone et al. (2005) and Boone (2008a) and firm- and industry-level PCM, are robust in a regression model that tries to link competition intensity to innovation.

\footnotetext{
${ }^{13}$ The "quality" of competition is important and related to the measured distance to the technology frontier. However, we don't make any difference between, nor control for, factors other than the distance to the technology frontier (DTF) that would influence the quality of competition (e.g. the modus of entry, product or process innovation). The DTF captures all these aspects, perhaps in different ways. If one form of "innovation" is more closely associated with a lower or higher DTF is still an open question. That being said, if measured DTF is more closely associated with product innovations, then our results would be expected to follow the results on product innovation from Vives (2008), ceteris paribus.

${ }^{14}$ This model is a firm-level transposition of Griffith et al. (2006) which looks the relationship between competition and innovation at the industry-level.
} 
Given the data available, we implement the model from Eq. 1 with this reduced form equation ${ }^{15}$ :

$$
\begin{aligned}
\operatorname{Ln}\left(R \& D_{f i t}\right)= & \alpha_{1}+\alpha_{2} \operatorname{COMP}_{(f) i t}+\alpha_{3} D T F_{i t}+\alpha_{4} \operatorname{COMP}_{(f) i t} \times D T F_{i t}+\beta \ln (L)_{f i t} \\
& +\gamma \ln \left(\frac{K}{L C}\right)_{f i t}+\theta\left(\frac{S}{L_{R}}\right)_{f i t}+\delta_{t}+\delta_{i}+\eta_{f}+\varepsilon_{f i t}
\end{aligned}
$$

The indicator of innovation is firm $\mathrm{R} \& \mathrm{D}$ expenditures, COMP is an indicator of competition measured at the firm- or industry-level, DTF stands for the industry's distance to technology frontier, $L$ denotes labour and control for the size of the firm, ${ }^{16} K$ is the tangible and intangible capital stock, LC represents the labour cost, $S$ represents the skilled workforce. The remaining parameters are time, industry and firm fixed effects. ${ }^{17}$

One concern with this basic set-up is causality. Competition may be a determinant of firms' innovative behaviour, but the innovative performance of firms may conversely affect the competitive pressure. Ideally, we would have a first stage equation explaining competition by additional "exogenous" variables (possibly related to quasi-natural experiment policy related shocks that alter the competitive pressure faced by firms). However, our dataset does not present an obvious choice of such an instrument, and it was impossible to evaluate empirically the potential bias that could follow from causality.

Another concern with Eq. (2) is endogeneity. Endogeneity (i.e. one or more right hand side covariates correlate with the error term $\varepsilon$ ) could results in biased regression estimates. In theory, endogeneity could be produced by period effects (i.e. after covariates changed there were systematic shocks over time), unobserved heterogeneity (e.g. through omitted variables), simultaneity (i.e. random shocks trigger the change in covariates), and measurement error (i.e. errors in measuring covariates). In our case, firm's unobserved heterogeneity is probably the factor that could most likely be a problem in term of endogeneity. ${ }^{18}$ Fortunately, panel data allow to control for individual unobserved heterogeneity. But panel data alone cannot fix the problem of unobserved heterogeneity. Several estimation methods for panel data will remove or at least mitigate the possible endogeneity bias. These methods no longer use the between-firm comparison but instead they use within-firm changes: If competition intensity changes, how much does R\&D expenditure change (within one firm)? Therefore, unobserved differences between firms no longer bias the estimator and time-constant unobserved heterogeneity is no longer a problem. Since accounting for firm effects controls for any omitted variables that are constant over time, Eq. (2) will be estimated by a fixedeffects (FE) estimator. ${ }^{19}$ The FE estimator still rests on the assumption that Cov(covariates, $\varepsilon)=0$. If this assumption is violated, the FE estimator will be biased. Endogeneity in this sense could still be a problem even with panel data.

\footnotetext{
${ }^{15}$ As an alternative, we also ran a similar specification with $\mathrm{COMP}_{\text {it }}{ }^{2}$ in order to test for the non-linearity of the results and the results were inconclusive.

${ }^{16} \mathrm{~L}_{\mathrm{R}}$ represents the total of employees engaged in $\mathrm{R} \& \mathrm{D}$, While $\mathrm{L}$ denotes the total employees of the firm.

${ }^{17}$ Note that industry fixed effects (using the Pavitt classification) were used when firms changed industries over time. Otherwise, they would have no time variation, and could therefore be dropped from the analysis. ${ }^{18}$ The degree of endogeneity could also be closely related to the choice of the variable representing competition pressure. We believe that the price cost margin (PCM) measure is more subject to introduce endogeneity in the system than the Boone price elasticity (PE) measure as the latter better captures firm's heterogeneity in competition.

${ }^{19}$ Time-varying unobserved heterogeneity could still be a problem for the FE estimator.
} 


\section{Data}

In this paper, we used an experimental enterprise micro-data set developed by Statistics Canada as a pilot project. $^{20}$

The data set combines annual administrative and survey databases of enterprises in Canada. The data set links the records from the Business Register (BR), the Longitudinal Employment Analysis Program (LEAP), the Research and Development in Canadian Industry Survey, the Exporter Register and the General Index of Financial Information (GIFI) databases. The LEAP database provides a longitudinal source of information on employment, salaries, births and deaths of enterprises. A deterministic record linkage procedure is used to link the BR, LEAP, RDCI, Exporter Registry and GIFI datasets where the Business Number (BN) and the Business Register Identification Number (BRID) is used as the key identifiers.

The BR is the central repository of information on businesses in Canada. It is used as the principal frame for business statistics at Statistics Canada and contains a complete, up to date and unduplicated list on all active businesses in Canada that have a corporate income tax (T2) account, are an employer or have a Goods and Services Tax account with the Canada Revenue Agency. The BR provides a comprehensive set of stratification variables such as industrial classification, revenue, number of employees and total assets. ${ }^{21}$

GIFI provides financial statement information for all businesses in Canada from their income tax files. Data are extracted from administrative files of corporate taxation records in the form of T2 Corporation Income Tax returns and completed with information from other Statistics Canada surveys.

The LEAP database contains employment information for each employer business in Canada and has the advantage of covering the entire economy. It includes the approximately 1 million companies in the commercial economy that paid more than $\$ 1$ in payroll to employees. LEAP is a longitudinal file of companies (legal entities in the taxation system), not establishments. For each business, annual estimates of total payroll and employment are calculated. ${ }^{22}$

RDCI provides information on the expenditures and personnel devoted annually to scientific research and development (R\&D) by Canadian enterprises and non-profit industrial research institutes and associations. RDCI contains all firms known or believed to be involved in the performance or funding of $R \& D{ }^{23}$ Firms are identified most frequently from the Canada Revenue Agency T661 claim form administrative records used for claiming the Scientific Research and Experimental Development (SR\&ED) tax credits. ${ }^{24}$

Given the information available in this linked database, we limited the empirical analysis to the Canadian manufacturing sector for the 2000-2005 period. The dataset consists of an unbalanced $^{25}$ panel of 26,947 enterprise-year observations. An authorized abridged version of the summary statistics for the variables we used can be found in Table 1 (Appendix 2).

\footnotetext{
${ }^{20}$ A general description of the dataset is available under "Analysis of Business Behavior" at http://www. statcan.gc.ca/record-enregistrement/2008-eng.htm\#a4.

${ }^{21}$ For more detailed information, see http://www.statcan.gc.ca/cgi-bin/imdb/p2SV.p1? Function $=$ getSurvey $\&$ SDDS $=1105 \&$ lang $=$ en $\& \mathrm{db}=$ imdb $\&$ adm $=8 \&$ dis $=2$.

${ }^{22}$ For more detailed information on LEAP, see http://www.statcan.gc.ca/cgi-bin/imdb/p2SV.p1? Function $=$ getSurvey $\&$ SDDS $=8013 \&$ lang $=$ en $\& \mathrm{db}=\mathrm{imdb} \& \mathrm{adm}=8 \& \mathrm{dis}=2$.

${ }^{23}$ Some firms might not be observed for some years as information on R\&D spending data might not be available for every year.

${ }^{24}$ More information on this database can be obtained here: http://www.statcan.gc.ca/cgi-bin/imdb/p2SV.pl? Function $=$ getSurvey $\&$ SDDS $=4201 \&$ lang $=$ en $\& d b=i m d b \& a d m=8 \&$ dis $=2$

25 The fixed effect (FE) estimator can be applied to unbalanced data with little adjustments if the error term has mean zero conditional on past, current and future values of the regressors (Baltagi 2001).
} 
All economic variables are expressed in real terms (constant prices with base year 1997= 100). The general producer price index was used for most variables except for the tangible capital and the intermediate inputs. We used the price index for expenditures on capital investments (machinery and equipment + construction) and for the tangible capital, and the producer price index for intermediate goods for the intermediate inputs.

\subsection{Innovation}

We measured innovation using the R\&D expenses of firms (in natural $\log$ ). This variable comes from the RDCI survey. Only firms that had at least \$1 in R\&D spending are included in the sample.

\subsection{Competition intensity}

We used three different measures of competition in this paper, industry price cost margin, firm price cost margin, and a relatively new indicator of profit elasticity.

\subsubsection{The first competition measure we use is the traditional industry price-cost margin (PCM). We calculate it as follows}

$$
\mathrm{PCM}_{\mathrm{it}}=\sum_{f \in N_{i t}} S_{f i t}\left(\left(\text { Sales }_{\mathrm{fit}}-{\text { Operating } \left.\left.\text { Expenses }_{\mathrm{fit}}\right) / \text { Sales }_{\mathrm{fit}}\right)}\right.\right.
$$

where $\mathrm{S}_{\mathrm{ft}}$ is the market share of each firm within its industry, calculated as

$$
\mathrm{S}_{\mathrm{fit}}=\text { Sales }_{\mathrm{fit}} / \sum_{f \in N_{j t}} \text { Sales }_{f i t}
$$

Industry PCM is a popular indicator, but it also has some limitations in gauging competition intensity which have been well documented since Demsetz (1973). Demsetz argues that the indicators fail to take account the equilibrium effects of heterogeneity in marginal costs across firms on industry measures of market power, and are liable to misinterpret changes in competition intensity. More specifically, PCM incorrectly interpret the re-allocation of market shares towards more efficient firms with higher margins as a decline in competition intensity, whereas in reality, the industry is more competitive because of lower barriers to entry.

Boone $(2000 ; 2008$ b) shows that when competition intensifies in an industry (e.g. due to a fall in barriers to entry in the industry, or due to more aggressive interaction between firms), the more efficient or productive firms will take advantage of the more competitive environment and take over the market share of less efficient firms. As a result, $\mathrm{PCM}_{\mathrm{it}}$ in the industry will increase. In other research, he also shows that that the higher the levels of concentration an industry has, the more likely are price-cost margins will mis-measure changes in competition intensity. This point is particularly relevant for Canadian studies, since many industries in Canada are highly concentrated.

In order to measure competition more robustly, we use two additional variables that do not have the theoretical or empirical weaknesses of industry PCM. 
3.2.2 Boone's PE is a measure of competition proposed in Boone (2000; 2008a, b). To calculate it, we estimate the coefficients $\widehat{\beta}_{i t}$ s from the following regressions (for each industry $i$ and year $t$ ) of the form

$$
L n \Pi_{f i t}=\alpha_{i t}+\beta_{i t} \operatorname{LnAVC_{fit}}+\delta_{i t} L n L_{f i t}+\varepsilon_{f i t}
$$

where $\Pi_{f i t}$ are firm profits, $\mathrm{AVC}_{f i t}$ are average variable costs, and $\mathrm{L}_{f i t}$ is a variable controlling for the size of the firm. A higher absolute value of $\widehat{\beta}_{i t}$ indicates a greater sensitivity of firm profits to costs and higher competition intensity.

As in Boone et al. (2005), we used the Average Variable Costs (AVC) as a proxy for the marginal cost. ${ }^{26}$ We also estimated profits $\Pi$ as Sales minus the Operating Expenses, and Average Variable Costs (AVC) as Operating Expenses divided by Sales. These variables come from the GIFI, and the employment (L) variable comes from the LEAP survey. In order to calculate the AVC, we eliminated from the sample firms with less than $\$ 1$ sales (basically firms with $\$ 0$ sales). Firms with less than $\$ 1$ in operating expenses were also deleted. ${ }^{27}$

We expressed both variables ( $\Pi$ and AVC) in natural logarithms to obtain a comparable scale for the dependent and independent variables and to avoid outliers that have too much effect on the estimated slopes $\left(\widehat{\beta}_{i t} \mathrm{~s}\right)$. Taking the logarithms of the profits implies that all firms with losses or profits smaller than 1 have to be deleted from the sample. In order to correct for these missing firms, we applied a two-step Heckman estimator. ${ }^{28}$ To ensure robust Boone index estimates, industries that did not have 10 firm observations per year were also omitted from the dataset.

\subsubsection{Firm-level price cost margin $(P C M)^{29}$ is another measure of competition intensity that} we used. We computed this measure using the following formula

$$
\mathrm{PCM}_{\mathrm{fit}}=\left(\text { Sales }_{\mathrm{fit}}-\text { Operating Expenses }_{\mathrm{fit}}\right) / \text { Sales }_{\mathrm{fit}}
$$

\subsection{Distance to the technology frontier (DTF)}

The heterogeneity of firm characteristics cannot be explained only by competitive pressure. Generally speaking, firms perceiving their environment as competitive will tend to develop superior market learning allowing them to achieve greater performance. But the strategic type (i.e., innovator, imitator) adopted by the firm also depends of its relative position within the industry. The size of the technology gap between firms within an industry could affect its incentive to innovate.

To measure the size of the technology gap between firms within an industry, we first calculated the highest Total Factor Productivity (TFP) within an industry defined by a 4 digit NAICS code. Because we do not have a measure of value added in the database, we estimated TFP using a measure of firm's output (Sales) relative to the Capital (tangible +

\footnotetext{
${ }^{26}$ It is possible to compute the same index using the median profit of an industry to express the relative profit of a firm. See CPB (2000). Boone et al. (2005) use the absolute values.

${ }^{27}$ Note that we have the same sample of firms when the two other competition variables are used.

${ }^{28}$ Further discussion of negative profit firms and their potential impact on the results of the study is found in section 4 .

${ }^{29}$ We used 1-PCM in regressions.
} 
intangible), intermediate inputs, and labour input (from RDCI). ${ }^{30}$ Thus, we probably underestimated the labour cost for each firm.

$$
\mathrm{TFP}_{\text {fit }}=\text { Sales }_{\text {fit }} /\left(\text { Capital }_{\text {fit }}+\text { Intermediate Inputs }_{f i t}+\text { Labour cost }_{\text {fit }}\right)
$$

For the Distance to the Technology Frontier, we let:

$$
\mathrm{DTF}_{\text {fit }}=\left(\mathrm{TFP}_{\mathrm{Fit}}-\mathrm{TFP}_{\text {fit }}\right) / \mathrm{TFP}_{\text {Fit }}
$$

where $\mathrm{F}$ denotes the frontier firm (with the highest TFP) and $\mathrm{f}$ denotes nonfrontier firms. ${ }^{31}$ So, at the firm level, $\mathrm{DTF}_{\text {fit }}>0$, and $\mathrm{DTF}_{\mathrm{Fit}}=0$.

Following Aghion et al. (2005), we use the average industry-level measure of neck-andneckness:

$$
D T F_{i t}=\sum_{f \in N_{i t}} \frac{D T F_{f i t}}{N}
$$

A lower value of $\mathrm{DTF}_{\mathrm{it}}$ indicates that firms in industry $i$ are on average closer to the technological frontier, while a higher value of $\mathrm{DTF}_{\text {it }}$ indicates a large technological gap between the leader and the other firms within the industry. Of course the technological frontier measure is a relative one since it is determined by the firm with the highest TFP within an industry. It is possible to imagine a situation where all firms within an industry would be far from a more objective measure of the technological frontier. But this relative measure suits our needs since competitors are likely to be within the same industry.

Although the data allows the use of a firm level DTF measure in the regressions based on the interpretation of Aghion et al. (2001) which suggests that the industry level variable may better reflect the expected payoff of catching up to the frontier for any firm in an industry. The industry level variable takes into account the average clustering in the distribution of the DTF in the industry, rather than only considering the distance from the laggard to the technological leader. In a previous version we also considered the distance from the frontier at the firm level. The results were similar with an even stronger effect of DTF on R\&D spending.

\subsection{Labour (not labour cost)}

For this variable, we used the natural log of total employment figures from the LEAP database. Firms with no employee were removed from the sample. We lost very few observations.

\subsection{Capital -labour cost ratio}

To measure Capital-Labour ratio we used the GIFI and RDCI databases. Capital value is the sum of the Tangible and the Intangible capital, and the Labour Cost is represented by Wages and Salaries from the RDCI database. Since we probably underestimated the labour cost, we could have overestimated the ratio.

\subsection{Proportion of skilled workforce}

A more skilled workforce will stimulate productivity and innovation. We used the proportion of Master's and Ph.D.s of all employees performing R\&D to compute this variable. In Eq.

\footnotetext{
${ }^{30}$ Although GIFI has a more reliable measure of labour cost, too many observations are lost because of missing data elements. Regressions were run with the later and results were similar.

${ }^{31}$ It is important to note that in order to eliminate statistical outliers from the data we instituted a $95 \%$ cut off level for $\mathrm{TFP}_{\text {fit }}$. The TFP value at the 95 th percentile then became the new technological frontier $\left(\mathrm{TFP}_{\mathrm{Fit}}\right)$.
} 
(2), S represents the number of employees with a Master's or a Ph.D. and $\left(L_{R}\right)$ represents the number of employees doing R\&D (which is different from the firm's total number of employees, L). These variables came from RDCI.

\subsection{Industry classification}

In computing the indices, we use the 2002 NAICS industry classification at the 4-digit level. NAICS codes came from the BR database. For the industry dummies (control variables) we used a modified definition from Pavitt (1984)'s taxonomy, which classifies sectoral patterns of innovation into three sectors. The sectors were later increased or reclassified into five sectors (see appendix 1): The supplier dominated category was broken into Resources and Labour; the production intensive was defined as Scale-intensive and Specialized suppliers; and the Science-based remained a single category. Firms in the supplier dominated category are traditionally characterized as having a low to medium-low technology orientation. Innovation therefore depends on external factors, such as suppliers of equipment and materials. Firms in the scale intensive sector have some in-house development capability. They interact mostly with specialized supplier firms where the level of technology is higher.

\section{Results}

Table 2 (Appendix 3) shows a summary of the main regression results. Results for the firms, year and industry fixed effects are not reported since they are of no interest. All results presented here use an unbalanced panel of 26,947 observations of enterprises from 2000 to $2005 .^{32}$

Table 2 displays the results using three different measures of competition intensity: industry-level price-cost margins (columns 1 and 2), firm-level price-cost margins (columns 3 and 4), and the Boone PE (columns 5 and 6). Note that apart from the estimated coefficients of competition and the distance to the technological frontier (DTF), the size and significance of all variables are highly stable for all measures of competition intensity.

Every variable in the regression has the expected sign except for the capital-labour ratio in the firm level PCM regressions. For the Boone and industry PCM regressions, the signs of the capital-labour ratio were right but with no statistical significance. This could be due to the underestimation of the labour cost and the overestimation of the capital-labour ratio (and potentially a bias) since we used a variable from the RDCI survey that only provides information about the wages and salaries of R\&D employees. ${ }^{33}$ Not surprisingly, the proportion of skilled workforce is strongly statistically significant and shows a large positive impact on R\&D spending. The remaining control variables are statistically significant but are of less interest. The size of the firm calculated by the natural log of employment has a positive impact on $R \& D$ performance. Industry dummies have a negative impact on $R \& D$ spending because the reference category is a science-based industry. The economic significance of these findings has been extensively discussed elsewhere in the literature.

\footnotetext{
32 See section 3 for more details on the data.

33 Although a better variable is technically available in the GIFI, there were too many missing observations to use it. Moreover, when we used the direct ratio instead of the log form of the capital-labour ratio, the Boone and industry PCM regressions showed a positive and significant impact of the capital-labour ratio on R\&D spending (without significantly affecting the other parameters in the regressions).
} 


\subsection{Competition and innovation: main results}

Using alternative competition measures produces the same results for the DTF coefficient: it is always negative and statistically significant. This suggests that R\&D expenditures decrease with the DTF, an observation consistent with the predictions of Aghion et al. (2005). Firms far from the technological frontier do not have to spend as much on R\&D in order to compete. Rather, in order to compete, resources are more efficiently spent on the adoption of technologies.

The results for the competition intensity variables are nearly as strong. In all columns but (2) in Table 2, the competition coefficient has a positive value and statistical significance. This suggests that higher competition intensity is associated with higher firm R\&D spending.

However, the interaction term coefficient $\alpha_{4}$ in Eq. 2, which affects the marginal impact of both competition intensity and DTF on firm innovation, is important to correctly interpret the results. These two variables interact if the effect of one of the variables differs depending on the level of the other variable. For the firm level PCM and Boone PE measures, the interaction term is negative and statistically significant. This suggests that greater competition intensity reinforces the negative marginal effect of DTF on firm R\&D spending. More importantly, it suggests that greater heterogeneity in technical efficiency (higher DTF) would reduce the marginal positive impact of competition intensity on firm R\&D spending. Evaluated at the sample mean of the DTF (see Appendix 2), the marginal impact of competition intensity on R\&D expenditures is positive. However, if many firms in an industry are technological laggards and DTF is high enough, the overall marginal effect of competition intensity on innovation could be negative and an increase in competition intensity would reduce firm $R \& D$ spending.

\subsection{Competition and innovation: discussion}

Our results suggest that heterogeneity in technical efficiency levels within an industry (here measured through the distance-to-frontier) is an important driver of both innovation efforts directly, and of equilibrium competitive pressure. In other words, being a laggard or a leader influences your R\&D efforts by altering the competitive pressure that determines the trade-off between the pre-innovation and post-innovation rents. To our knowledge, empirical evidence of this feature of competition, sometimes discussed in the context of theoretical models of imperfect competition, has rarely been raised in the literature on business innovation.

As well, our results suggest a Schumpeterian interpretation by showing that higher DTF reduces the positive marginal effect of competition intensity on innovation - that is, the farther the majority of firms in an industry are from the technological frontier (and, presumably, from higher efficiency and higher profitability), the less they innovate. In other words, competition intensity has a strong positive impact on business R\&D only when competition in the industry is among equals. This interpretation is consistent with other findings in the literature, such as the 'inverted-U' of Aghion et al. (2005).

Both the firm level PCM and Boone measures produce the same qualitative results with the same Schumpeterian interpretation. The Boone index measure, however, presents broader implications to the results, since we know (via the non-zero DTF measure) that competition in Canadian industries is mostly not among equals. The Boone index embodies the heterogeneity of firms in an industry and the degree of felt competition to a greater extent than the firm level PCM, which only observes the market power of one firm at a time. In this sense, the agnostic nature of the Boone index contributes to a more robust interpretation of the results.

Some economic studies imply that firms that are far from the technological frontier (i.e. those with a greater DTF) may have less to gain from R\&D expenditures than technology leaders. By adopting new 'off-the-shelf' technologies they may easily catch-up with the TF 
with few $R \& D$ expenditures and then subsequently increase their investments in $R \& D$ as the literature on the complementarity between technology adoption and innovation suggests. ${ }^{34}$ The literature is rather vague about the outcomes of possible dynamic non-linearities that can arise when competition forces a firm to catch-up in the context of firm heterogeneity. For example, Sutton $(1991 ; 1998)$ produces non-linear predictions for the impact of changes in competition intensity on certain types of industries - namely, that an increase in competition intensity will produce an escalation in $\mathrm{R} \& \mathrm{D}$ spending, followed by a contraction process, as some firms that are unable to maintain the increased expenditure are forced to leave the market. In fact, Ershov (2009) finds empirical evidence that such dynamics can be an important factor in explaining the impact of competition intensity on business R\&D expenditures.

\subsection{Robustness analysis}

\subsubsection{TFP and DTF cut off}

One of the sensitivity issues that concerned us was the cut-off value applied to the Total Factor Productivity (TFP) proxy (that is used to calculate the average DTF). When no cut off was used, mean DTF value was naturally higher. The negative coefficient of the interaction term between competition intensity and DTF was smaller but the marginal net effect of

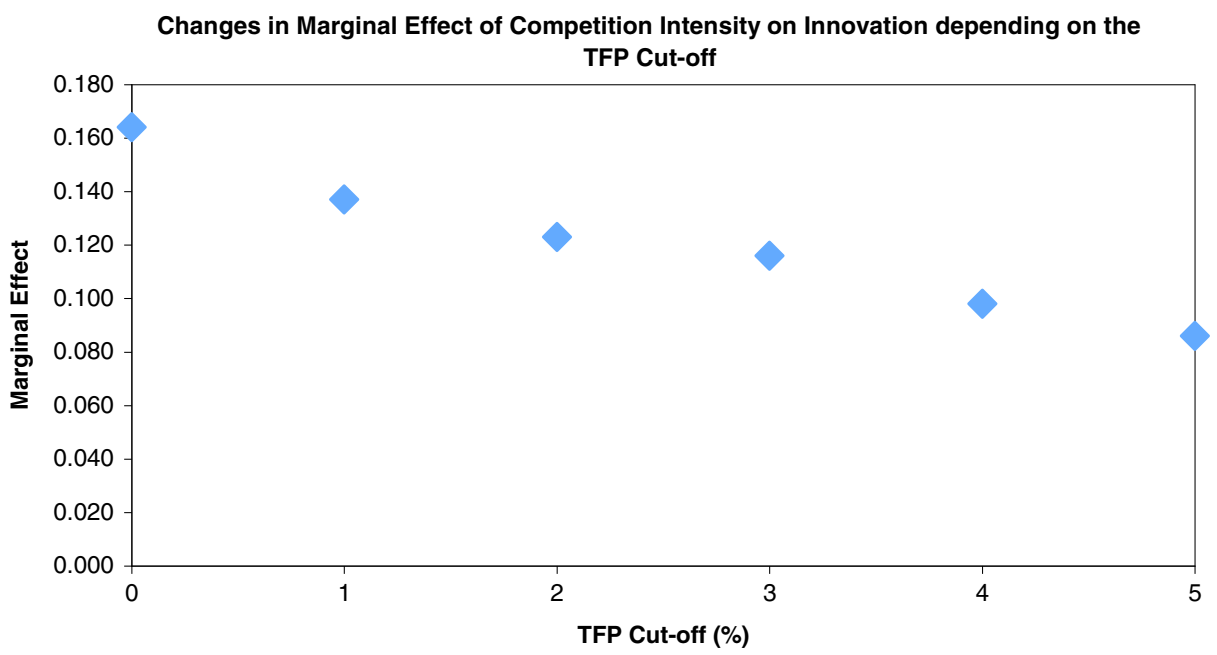

competition on innovation, now measured at a higher sample DTF mean, was still positive.

The following chart shows the marginal effect of competition intensity on innovation (via the Boone index) and how it changes based on changes in the cut-off values.

We found that the interaction between competition and Distance to Frontier was not significant anymore when we used a smaller cut off $(0 \%, 1 \%$ and $2 \%)$. This lack of robustness forces some questions concerning whether the cut off eliminates actual statistical outliers and computation errors, or simply eliminates legitimate observations of 'world

$\overline{{ }^{34} \text { For example, see Brynjolfsson }}$ and Hitt (2000). 
leading companies'. Since this problem is present on the national scale, it would likely be even worse on the global scale when considering global technological leaders.

Our analysis suggests that instituting a cut off can affects the final results but not the general conclusions of the study. One exception arose when at the beginning of the study we failed (due to missing data at this point) to include intermediate inputs in the TFP calculations. Failing to include intermediate inputs in the TFP calculations (over estimating TFP's) gave us a very high DTF mean with a small negative marginal effect of competition on innovation.

The results and the existing literature already hinted us that increasing competition when firms are far from the technological frontier would induce less spending in R\&D. If these firms have an inclination to imitate, they probably use relatively more intermediate inputs than firms that are neck-and-neck at the technology frontier (that probably use relatively more capital). This would explain why we found a small negative marginal effect of competition on innovation when we excluded the intermediate inputs from the TFP calculations (whatever cut off between $0 \%$ and $5 \%$ we may use).

So, more than the cut off itself, the definition of the Total Factor Productivity and the Technological Frontier (and how we measure the distance from it), could potentially lead to different conclusion about the net marginal effect of competition on innovation.

\subsubsection{More on the TFP measure}

Our index proxy for TFP is flawed when it comes to modelling the technological frontier of an industry and the location of different firms on the distribution of technology in an industry, since it does not actually consider how 'high-tech' a firm is, but only its ratio of sales to costs. An example of its limitations would be a start-up firm which has low sales, but which also pushes the technological frontier forward by investing heavily in R\&D (thus incurring high costs). As a result, our TFP value for this company would be low and its individual DTF value would be high, despite the fact that in reality it is actually on the frontier. If there are many such firms, the model could, therefore, misrepresent the state of the technological frontier and the DTF of an industry.

It would be preferable to estimate TFP values using another method, such as a Solow residual. Due to insufficient data, this is currently impossible.

\subsubsection{Negative profit observations}

As mentioned above, all negative profit observations were eliminated from the sample. This does not have an effect on the Boone index since this measure naturally takes into account the effects of the competitive behaviour of negative profit firms on positive profit firms, ${ }^{35}$ and since we also corrected for the presence of negative profit firms using a two-stage Heckman estimator. It does, however, affect the firm level PCM. If negative profit observations are included in the sample, firm level PCM becomes unbounded from below, and that would affect its statistical properties and its impact on the final regression.

The Boone index led us to the same conclusion whether we included the negative profit firms or not. This was clearly not the case with the other two measures of competition intensity.

Negative profit observations also had some impact on the calculation of the DTF measure (around 2\%) but not enough to change the results.

\footnotetext{
${ }^{35}$ For example, if firms with negative profits in an industry are aggressive price-setters, then the positive profit firms would also have to price aggressively, and this behaviour would be reflected in the Boone index measure.
} 


\section{Conclusion}

There is a growing literature on the importance of a non-monotonic relationship between competition and innovation for economic growth. This literature emphasizes the importance of heterogeneity in the technical efficiency of firms within an industry in order to understand the complex relationship between competition intensity and innovation. By incorporating firm heterogeneity into the analysis via a relative distance to the technological frontier measure, this paper finds empirical evidence suggesting a Schumpeterian interpretation of the impact of competition intensity on innovation.

Although the direct interpretation of competition intensity measures suggests that competition is positively associated with business expenditures on $\mathrm{R} \& \mathrm{D}$, these measures treat competition as symmetric and identically felt for all firms in the industry, which is generally not the case. Put simply, competition in an industry is not only competition among equals, but also competition between laggards and laggards, leaders and leaders, and laggards and leaders, which has considerable differences with regards to its impact on innovation activity. High competition felt by low margin firms which are far away from the frontier has a very different impact on innovation than low competition felt by high margin firms which are on technological frontier.

When incorporated in the analysis, the distance of firms from the technological frontier of an industry has a strongly negative impact on innovation, both directly, and by dampening the positive marginal effects of competition intensity. Jointly, this indicates that the further the bulk of the firms in an industry are from the technological frontier, the less high competition will affect firm incentives to innovate - a variant on the classic Schumpeterian interpretation that higher profitability and efficiency produces more innovation.

In our view, this research suggests three major areas of future research. First, these newly available rich micro-datasets allow researchers to revisit some important empirical regularities or stylized facts about business innovation in light of our capacity to control for the heterogeneity in firm level technical efficiency. Second, this research also outlines the potential to enrich existing empirical models of business innovation with structural estimation that would enhance our capacity to make causal inferences about the effects of competitive pressure not only on business innovation, but also on technology adoption in Canada. Third, the general result raises additional questions concerning the impact of competition intensity on innovation in conjunction with firm heterogeneity for specific industries or industry groups. Identifying the industries in which firms could benefit from getting closer to the frontier or facing more competition would be an asset in developing more efficient policies that promote business innovation. Finally, this research also raises the importance of developing richer longitudinal business micro-data sets that would allow researchers to investigate the factors that motivate and drive firms to (i) catch-up to the technology frontier and (ii) decide to adopt and implement business strategies based on innovation.

\section{Appendix 1}

Pavitt industry classification taxonomy

\begin{tabular}{lll}
\hline Pavitt taxonomy & NAICS code & Description \\
\hline Resource-intensive & 311 & Food Manufacturing \\
& 312 & Beverage and Tobacco Product Manufacturing \\
321 & Wood Product Manufacturing \\
& 322 & Paper Manufacturing
\end{tabular}




\begin{tabular}{|c|c|c|}
\hline Pavitt taxonomy & NAICS code & Description \\
\hline & 324 & Petroleum and Coal Product Manufacturing \\
\hline & 327 & Non-Metallic Mineral Product Manufacturing \\
\hline \multirow[t]{7}{*}{ Labour-intensive } & 313 & Textile Mills \\
\hline & 314 & Textile Product Mills \\
\hline & 315 & Clothing Manufacturing \\
\hline & 316 & Leather and Allied Product Manufacturing \\
\hline & 332 & Fabricated Metal Product Manufacturing \\
\hline & 337 & Furniture and Related Product Manufacturing \\
\hline & 339 & Miscellaneous Manufacturing \\
\hline \multirow[t]{9}{*}{ Scale-intensive } & 323 & Printing and Related Support Activities \\
\hline & 325 & Chemical Manufacturing \\
\hline & 331 & Primary Metal Manufacturing \\
\hline & 3361 & Motor Vehicle Manufacturing \\
\hline & 3362 & Motor Vehicle Body and Trailer Manufacturing \\
\hline & 3363 & Motor Vehicle Parts Manufacturing \\
\hline & 3365 & Railroad Rolling Stock Manufacturing \\
\hline & 3366 & Ship and Boat Building \\
\hline & 3369 & Other Transportation Equipment Manufacturing \\
\hline \multirow[t]{2}{*}{ Science-Based } & 334 & Computer and Electronic Product Manufacturing \\
\hline & 3364 & Aerospace Product and Parts Manufacturing \\
\hline \multirow[t]{2}{*}{ Specialized } & 333 & Machinery Manufacturing \\
\hline & 335 & Electrical Equipment, Appliance and Component Manufacturing \\
\hline
\end{tabular}

\section{Appendix 2}

Table 1 Summary statistics, 2000-2005

\begin{tabular}{llll}
\hline Variables & $\mathrm{N}$ & Mean & Std dev \\
\hline LRDexp (R\&D expenses) & 26,974 & 11.5871 & 1.5617 \\
COMP = -Boone index & 26,974 & 0.6571 & 0.2842 \\
COMP = (1-PCM) & 26,974 & 0.2945 & 0.1729 \\
COMP = (1-PCM) at naics 4 digits & 26,974 & 0.2103 & 0.0631 \\
DTF Distance to Tech. Frontier & 26,974 & 0.4755 & 0.0727 \\
Ln (L) Employment & 26,974 & 3.6512 & 1.5521 \\
Ln (K/Lc) Capital labour ratio & 26,974 & -0.7968 & 1.0861 \\
Sk/L Skill ratio & 26,974 & 0.0124 & 0.6196 \\
Resources based industry (inress) & 26,974 & 0.1563 & 0.3631 \\
Labour based industry (inlab) & 26,974 & 0.2874 & 0.4526 \\
Sclale intensive industry (inscal) & 26,974 & 0.2370 & 0.4252 \\
Specialized industry (inspec) & 26,974 & 0.2142 & 0.4103 \\
Science-based industry & & Reference Cat.
\end{tabular}




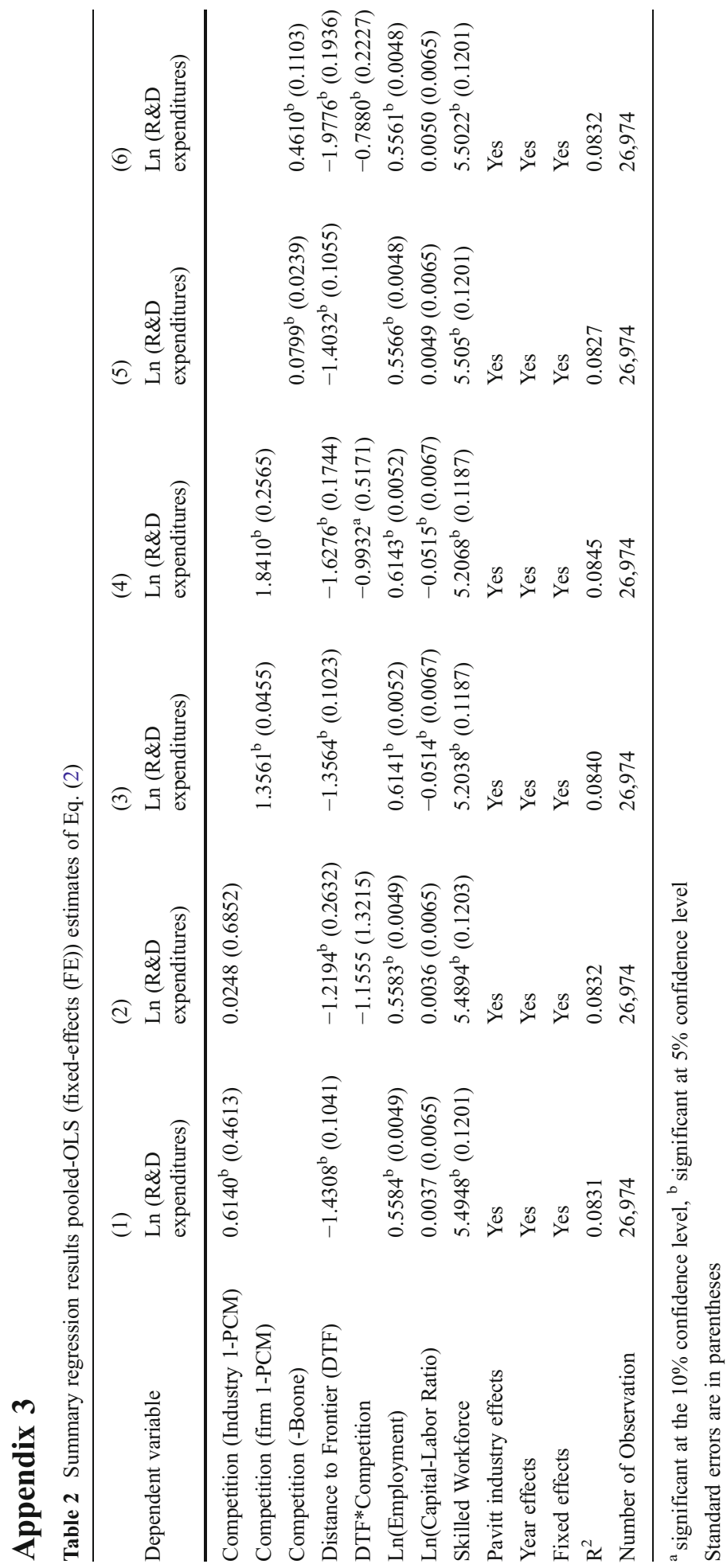




\section{References}

Acemoglu D, Aghion P, Zilibotti F (2006) Distance to frontier, selection, and economic growth. J Eur Econ Assoc 4(1):37-74, March Issue

Aghion P, Howitt P (1992) A model of growth through creative destruction. Econometrica 60(2):323-351

Aghion P, Harris C, Vickers J (1997) Competition and growth with step-by-step innovation: an example. Eur Econ Rev 41(3-5):771-782

Aghion P, Harris C, Howitt P, Vickers J (2001) Competition, imitation and growth with step-by-step innovation. Rev Econ Stud 68:467-492

Aghion P, Bloom N, Blundell R, Griffith R, Howitt P (2005) Competition and innovation: an inverted-U relationship. Q J Econ 12032(2):701-728

Arrow K (1962) Economic welfare and the allocation of resources for invention. In: The rate and direction of inventive activity: economic and social factors. Princeton, NJ: Princeton University Press

Baltagi BH (2001) Econometric analysis of panel data, 2nd edn. Wiley, New York

Blundell R, Griffith R, Van Reenen J (1999) Market share, market value and innovation: evidence from British manufacturing firms. Rev Econ Stud 66(3)

Boone J (2000) Competitive pressure: the effect on investments in product and process innovation. RAND J Econ 31(3):549-569

Boone J (2008a) A new way to measure competition. Econ J 118(531):1245-1261

Boone J (2008b) Competition: theoretical parameterizations and empirical measures. J Inst Theor Econ 164:587-611

Boone J, Griffith R, Harrison R (2005) Measuring competition. AIM Working Paper No. 22

Brynjolfsson E, Hitt L (2000) Beyond computation: information technology, organizational transformation and business performance. J Econ Perspect 14(4):23-48

Budd C, Harris C, Vickers J (1993) A model of the evolution of duopoly: does the asymmetry between firms tend to increase of decrease? Rev Econ Stud 60:543-573

CPB (2000) Measuring competition: how are cost differentials mapped into profit differentials?, Working paper no. 131, CPB Netherlands Bureau of Economic Research, the Hague

Dasgupta P, Stiglitz J (1980) Industrial structure and the nature of innovative activity. Econ J 90:266-293

Demsetz H (1973) Industry structure, market rivalry and public policy. J Law Econ

Dixit A, Stiglitz J (1977) Monopolistic competition and optimum product diversity. Am Econ Rev LXVII:297-308

Duhamel M (2011) What do we know about competition in Canada? Mimeo, Canadian Institute for Research on Public Policy and Public Administration, March

Duhamel M, Ershov D (2008) Benchmarking competition intensity in Canada and the US: estimating Boone's profit elasticities, 1985-2005, mimeo, Industry Canada

Duhamel M, Kelly R (2009) Are changes in the Boone and Lerner indices of competition correlated? Evidence from OECD Countries, mimeo, Industry Canada

Ershov D (2009) Explaining the innovation intensity gap between Canada and the United States using endogenous sunk costs, mimeo, Industry Canada

Geroski P (1995) Market structure, corporate performance and innovative activity. Oxford University Press

Griffith G, Harrison R, Simpson H (2006) Product market reform and innovation in the EU, mimeo

Grossman GM, Helpman E (1991) Innovation and growth in the global economy. MIT Press, Cambridge

Hall RE (1988) The relation between price and marginal cost in U.S. industry. J Polit Econ 96(5):921-947

Levin R, Cohen W, Mowery D (1985) R\&D appropriability, opportunity and market structure: new evidence on some Schumpeterian hypotheses. Am Econ Rev Papers Proc 75:20-24

Loury G (1979) Market structure and innovation. Q J Econ 93:395-410

Nickell S (1996) Competition and corporate performance. J Polit Econ, vol. 104

Pavitt K (1984) Sectoral patterns of technical change: towards a taxonomy and a theory. Res Policy 13:343-373

Reiss PC, Wolak F (forthcoming) Structural econometric modeling: rationales and examples from industrial organization. Handb Econ vol 5, (http://www.stanford.edu/ preiss/makeit.pdf)

Roeger W (1995) Can imperfect competition explain the difference between primal and dual productivity measures? Estimates for U.S. manufacturing. J Polit Econ 103(2):316-330

Romer P (1990) Endogenous technological change. J Polit Econ XCVIII:71-102

Salop S (1977) The noisy monopolist: imperfect information, price dispersion, and price discrimination. Rev Econ Stud XLIV:393-406

Scherer FM (1965) Firm size, market structure, opportunity and the output of patented inventions. Am Econ Rev 55:1097-1124

Scherer FM (1967) Market structure and the employment of scientists and engineers. Am Econ Rev 57:524531 
Schmalensee R (1989) Inter-industry studies of structure and performance. In: Schmalensee R, Willig RD (eds) Handbook of industrial organization, vol. 2. North-Holland, Amsterdam, pp 951-1009

Schmookler J (1966) Invention and economic growth. Harvard University Press, Cambridge

Schumpeter JA (1934) The theory of economic development. Transaction Publishers, New Brunswick

Scott J (1984) Firm versus industry variability in R\&D intensity. In: Griliches Z (ed) Chapter in R\&D, patents, and productivity. University of Chicago Press, Chicago

Spence AM (1984) Cost reduction competition, and industry performance. Econometrica 52:101-121

Sutton J (1991) Sunk costs and market structure. MIT Press, Cambridge

Sutton J (1998) Technology and market structure. Cambridge, MA

Symeonidis G (2002a) The effects of competition: cartel policy and the evolution of strategy and structure of the British industry. MIT Press, Cambridge

Symeonidis G (2002b) The effect of competition on wages and productivity: evidence from the UK. Mimeo, University of Essex

Thille H (2011) Measuring the performance of Canadian markets. In: Chen Z and Duhamel M (eds.) Industrial organization in Canada: empirical evidence and policy issues, chapter 3. McGill-Queen's University Press

Tirole J (1988) The theory of industrial organization. MIT Press, Cambridge

Vives X (2008) Innovation and competitive pressure. J Ind Econ, Blackwell Publishing, vol. 56(3): 419-469 